\title{
Pembuatan Aplikasi Dashboard Strategic untuk Perencanaan Kapasitas Pembangkit Listrik yang Terintegrasi di Pulau Madura
}

\author{
Addin Aditya ${ }^{1)}$ \\ 1) Program Studi Sistem Informasi, STIKI Malang \\ Jl. Raya Tidar No 100, Kota Malang 65146 \\ Email : addin@stiki.ac.id
}

\begin{abstract}
Abstrak
Penelitian ini bertujuan untuk membuat aplikasi Dashboard Strategic untuk merencanakan kapasitas pembangkit listrik di Pulau Madura berdasarkan pemodelan sistem dinamik. Sampai saat ini Pulau Madura masih bergantung pada pasokan energi dari Pulau Jawa yang dialirkan melalui kabel sirkuit yang dibentangkan dari Gresk menuju Kamal. Metode ini dinilai cukup riskan karena kabel terbentang di dasar laut yang merupakan jalur transportasi kapal dagang dan rentan kerusakan. Perlu adanya sebuah kajian mengenai potensi energi terbarukan agar Pulau Madura bisa menjadi pulau yang mandiri secara energi. Dengan adanya aplikasi ini diharapkan dapat membantu para pemangku keputusan dan Pemerintah setempat untuk merencanakan Pembangkit Listrik yang independent dalam rangka kemandirian energi dan peningkatan rasio elektrifikasi bagi Pulau Madura.
\end{abstract}

Kata kunci: pemodelan, dashboard strategic, energi terbarukan, sistem dinamik.

\section{Pendahuluan}

Sampai saat ini, energi listrik masih menjadi kebutuhan utama bagi masyarakat. Kebutuhan akan energi listrik saat ini berbanding terbalik dengan persediaan sumber energi yang terus menipis. Rasio elektrifikasi di Indonesia masih belum memenuhi asas keadilan dan pemerataan dikarenakan ketersediaan energi listrik tidak sebanding dengan kebutuhan masyarakat. Menurut data dari Kementerian Energi dan Sumberdaya Mineral (2014), saat ini terdapat 14 provinsi di Indonesia yang memiliki rasio elektrifikasi di atas 60\%, yakni Aceh $(76,98 \%)$, Sumatera Utara $(69,68 \%)$, Sumatera Barat (69.37\%), Bangka Belitung (72,88\%), Banten $(63,90 \%)$, Jakarta (100\%), Jawa Barat $(67,40 \%)$, Jawa Tengah (71,24\%), DIY (84,48\%), Jatim (71,55\%), Bali (74,98\%), Kalimantan Timur $(68,56 \%)$, Kalimantan Selatan (72,29\%) dan Sulawesi Utara (66,87\%). Sementara 14 provinsi lainnya memiliki rasio elektrifikasi berkisar antara 41\%-60\%. Provinsi yang termasuk kategori ini adalah Riau dan Kepri $(55,84 \%)$, Jambi (51,41\%), Bengkulu (51,46\%), Lampung $(48,82 \%)$, Sumatera Selatan $(50,30 \%)$, Kalimantan Barat $(45,83 \%)$, Kalimantan Tengah (45,22\%), Gorontalo (49,79\%), Sulawesi Tengah (48,30\%), Sulawesi Barat, Sulawesi Selatan (55,2\%), Maluku (54,51\%) dan Maluku Utara (49,44\%). Provinsi lainnya masih memiliki elektrifikasi antara $20 \%-40 \%$ yaitu Nusa
Tenggara Barat (32,51\%), Nusa Tenggara Timur $(24,55 \%)$, Sulawesi Tenggara $(38,09 \%)$ serta Papua dan Irian Barat $(32,35 \%)$.

Di provinsi Jawa Timur khususnya di Pulau Madura memiliki rasio elektrifikasi 59.02\%. Pulau Madura memiliki rasio elektrifikasi paling rendah di Jawa Timur. Keadaan ini disebabkan karena kecilnya jumlah penduduk di suatu desa dan jarak antar desa juga cukup jauh. Kedepannya, pemerintah Provinsi Jawa Timur menargetkan untuk meningkatkan rasio elektrifikasi Jawa Timur menjadi 77.16\%. Indonesia merupakan negara kepulauan terbesar di Asia. Keadaan ini menimbulkan masalah dalam pemerataan energi. Sistem tenaga listrik untuk daerah kepulauan memiliki kendala karena tidak bisa menggunakan sistem transmisi jaringan listrik antar pulau (Mayer, 2000).

Penelitian ini bertujuan untuk membuat aplikasi dashboard strategic untuk merencanakan kapasitas pembangkit listrik agar memenuhi kebutuhan energi listrik di Pulau Madura berdasarkan sumberdaya alam yang dimiliki oleh daerah tersebut. Aplikasi ini nantinya juga akan memetakan potensi sumberdaya alam yang dapat digunakan untuk membangkitkan energi listrik. Pendekatan yang digunakan untuk penelitian ini adalah pendekatan sistem dinamik. Alasan digunakannya sistem dinamik dikarenakan pendekatan ini memiliki beberapa kelebihan dibandingkan dengan metode peramalan konvensional. Kelebihan tersebut yaitu model sistem dinamik dapat memberikan perkiraan yang lebih handal dari model statistik serta menyediakan cara untuk memahami perilaku industri, mendetekai terhadap perubahan dini dan penentuan faktor-faktor yang meramalkan perilaku secara sensitif dan signifikan (Axella \& Suryani, 2012).

\section{Tinjauan Pustaka}

Permintaan energi listrik suatu daerah ditinjau dari tiga faktor: pertumbuhan ekonomi, rasio elektrifikasi dan transfer energi listrik ke sistem interkoneksi (Pamudji, 2014). PT PLN (Persero) selaku BUMN mewakili pemerintah dalam urusan energi listrik memiliki tanggung jawab untuk membantu program pemerintah dalam meningkatkan rasio elektrifikasi di Indonesia. 
Maka PLN wajib untuk memasok energi listrik sesuai dengan area kerja mereka.

\section{A. Kondisi Kelistrikan di Pulau Madura}

Sampai saat ini, sumber listrik Pulau Madura masih bergantung dari Pulau Jawa melalui dua sirkuit kabel bertegangan 150.000 volt berkapasitas 2 x100 mW yang terbentang dari Gresik menuju Kamala, Madura. Kabel transmisi ini sangat rentan terjadi kerusakan karena melewati Selat Madura yang menjadi jalur perdagangan dan dilewati oleh banyak kapal. Berdasarkan data dari PLN Distribusi Jawa Timur, di Madura terdapat sekitar 395.000 pelanggan listrik yang tersebar di Kabupaten Bangkalan, Kabupaten Sampang, Kabupaten Pamekasan dan Kabupaten Sumenep dengan pertumbuhan mencapai $2 \%$ per tahun. Saat ini PLN telah mengoperasikan Pembangkit Listrik Tenaga Gas berkapasitas 2x18 mw di Gili-Timur Kabupaten Bangkalan untuk antisipasi jika terjadi gangguan pada transmisi.

\section{B. Penelitian Terkait}

Menurut Axella (2012), ada beberapa variable yang dapat didefinisikan dalam perencanaan pembangkit listrik, yaitu: kapasitas pembangkit, jumlah pelanggan listrik, kapasitas penggunaan energi, harga bahan bakar,faktor beban, forced outage rate dan kapasitas faktor.

Pasokan energi listrik untuk Negara Indonesia masih belum dapat memenuhi kebutuhan permintaan energi listrik dikarenakan kondisi geografis yang kurang memungkinkan untuk memasok energi ke seluruh wilayah. Pasokan energi listrik untuk Pulau Madura dialirkan melalui kabel yang terbentang dari Gresik menuju Kamal. Kekurangan energi listrik dapat memaksa PT PLN untuk melakukan pemadaman bergilir di Pulau Madura (Anwar, 2011).

\section{Pembangkit Energi Listrik}

Sebagian besar pembangkit listrik bekerja dengan memutar generator. Mesin yang digunakan untuk memutar generator biasanya menggunakan diesel, turbin uap, sumber air dan gas alam (Marsudi, 2011). Generator elektrik ini merupakan konversi energi primer menjadi energi mekanis.

Terdapat beberapa jenis pembangkit:

1. Pembangkit Listrik Tenaga Air: pembangkit ini menggunakan sumberdaya air sebagai energi primer

2. Pembangkit Listrik Tenaga Uap: pembangkit ini menggunakan batu bara, minyak atau gas sebagai bahan bakar utama

3. Pembangkit Listrik Tenaga Gas: pembangkit ini menggunakan gas alam sebagai bahan bakar utama
4. Pembangkit Listrik Combined Cycle: pembangkit ini mengkombinasikan gas alam dan batubara untuk bahan bakar utama penggerak generator

Dalam memilih dan merencanakan pembangkit listrik, perlu diperhatikan beberapa kriteria, yaitu: prediksi pertumbuhan beban per tahun, karakteristik kurva beban, reliabilitas pembangkit, ketersediaan sumberdaya primer beserta harganya, aspek lingkungan, aspek sosial dan politik (Sutrisna \& Rahardjo, 2009)

\section{Pemodelan dan Simulasi}

Model merupakan representasi dari sistem yang sebenarnya. Suatu model dikatakan valid apabila model tersebut sudah mewakili sistem yang ada dengan tidak melanggar prinsip berpikir sistem. Dalam membangun sebuah model sangat dipengaruhi oleh subjektivitas seseorang atau organisasi, maka perlu adanya penyempurnaan yang dilakukan secara terus menerus dengan menggali informasi dan potensi yang relevan (Winardi, 1989).

Terdapat beberapa keuntungan apabila menggunakan konsep pemodelan dalam penelitian (Barlas, 1996):

1. Memungkinkan melakukan penelitian lintas sectoral

2. Dapat melakukan eksperimen terhadap sistem tanpa harus merusak sistem yang ada

3. Mampu menentukan tujuan aktivitas pengelolaan dan perbaikan terhadap sistem yang diteliti

4. Dapat digunakan untuk meramalkan perilaku dan keadaan sistem di masa datang

Pembuatan model pada umumnya dikerjakan dengan menggunakan perangkat lunak tertentu. Seperti Ventana simulation, stella, powersim dan lain sebagainya. Model dibuat dengan symbol-simbol atas variable dan hubungannya. Pola yang mempengaruhi keterkaitan antar unsur dijelaskan pada gambar berikut:

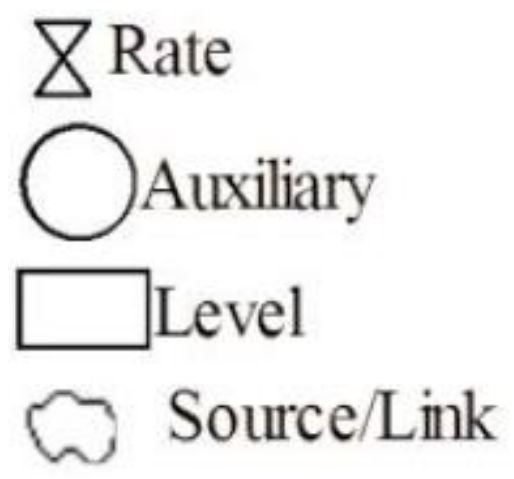

\author{
Gambar 1. Jenis Variable dan Pengaruhnya \\ Terhadap Model
}


Tahapan dalam mengembangkan model sistem dinamik diawali dengan pemahaman sistem dan permasalahannya dihubungkan sehingga membentuk lingkaran tertutup (hubungan sebab akibat) seperti yang terlihat pada gambar (Suryani, 2006):

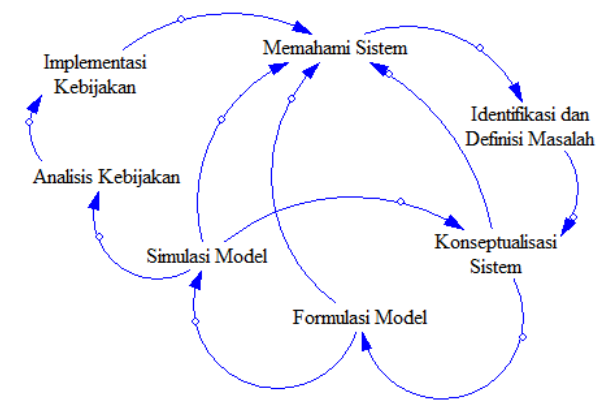

Gambar 2. Tahapan Pengembangan Sistem Dinamik

Proses validasi juga diperlukan dalam membangun sebuah model. Validasi berfungsi untuk membuktikan apakah model yang dibuat sudah mewakili / merepresentasi sistem nyata (Forrester, 1968). Terdapat dua cara dalam pengujian model, yaitu:

a. Perbandingan Rata-Rata (Mean Comparasion)

$$
E 1=\frac{|\bar{s}-\bar{A}|}{\bar{A}}
$$

Dimana:

S = Nilai Rata-Rata Hasil Simulasi

A = Nilai Rata-Rata Data

Model dianggap valid apabila $\mathbf{E} 1 \leq \mathbf{5 \%}$

b. Perbandingan Variasi Amplitudo (\% Error Variance)

$$
E 2=\frac{s g-s a}{s a}
$$

Dimana:

Ss $=$ Standard deviasi model

$\mathrm{Sa}=$ Standard Deviasi Data

Model dianggap valid apabila E2 $\leq \mathbf{3 0 \%}$.

\section{E. Aplikasi Dashboard}

Dashboard merupakan tampilan visual mengenai informasi paling penting yang diperlukan untuk mencapai suatu tujuan tertentu dan dapat diatur di satu layar sehingga lebih mudah untuk dipantau oleh user (Januarita \& Dirgahayu, 2015). Penggunaan istilah dashboard information adalah tampilan visual dari informasi penting yang diperlukan untuk mencapai satu atau lebih tujuan dengan mengkonsolidasikan dan mengatur informasi dalam satu layer sehingga kinerja organisasi dapat dimonitor dengan jelas.

Terdapat empat kriteria utama yang harus dimiliki dalam dashboard (Few, 2006):

1. Mengkonsolidasikan informasi bisnis yang relevan dan menyajikannya dalam satu kesatuan pandangan
2. Menyampaikan informasi yang akurat secara tepat waktu

3. Memberikan akses yang aman terhadap informasi yang sensitif

4. Memberikan solusi yang komprehensif

\section{Metode Penelitian}

Langkah-langkah yang dilakukan untuk menyelesaikan penelitian ini adalah sebagai berikut:

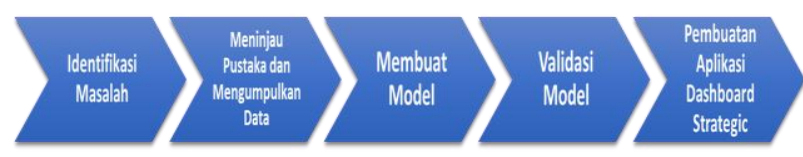

\section{Gambar 3. Tahapan Penelitian}

\section{Data Masukan}

Pada penelitian ini menggunakan data yang didapat dari hasil survey dan wawancara yang dilakukan di kantor PT. PLN (Persero) Distribusi Jawa Timur dan PT. PLN Area Pamekasan. Studi pustaka di Badan Pusat Statistik (BPS) Provinsi Jawa Timur juga merupakan literatur tambahan. Berikut informasi yang didapat:

1. Data pelanggan listrik Pulau Madura

2. Data Beban Puncak Pulau Madura

3. Laju Kenaikan Pelanggan Listrik

Dari data-data tersebut nantinya akan diproses menjadi model skenario kebijakan dengan bantuan software vensim.

\section{Identifikasi Variabel Terkait}

Berdasarkan tujuan dari penelitian ini, maka dapat didefinisikan beberapa variabel yang terkait. Beberapa aspek yang terkait untuk perencanaan kapasitas pembangkit listrik di Kepulauan Madura antara lain adalah pertumbuhan permintaan energi listrik, rasio elektrifikasi, beban puncak per wilayah dan reserve margin.

\begin{tabular}{|c|c|}
\hline $\begin{array}{l}\text { Tujuan } \\
\text { Penelitian }\end{array}$ & Variabel Terkait \\
\hline $\begin{array}{l}\text { Merencanakan } \\
\text { Kapasitas } \\
\text { Pembangkit } \\
\text { Listrik }\end{array}$ & $\begin{array}{l}\text { 1. Jumlah permintaan energi listrik } \\
\text { 2. Rasio elektrifikasi } \\
\text { 3. Jumlah pelanggan listrik } \\
\text { 4. Aspek sosial dan politik }\end{array}$ \\
\hline $\begin{array}{l}\text { Pembuatan } \\
\text { Dashboard } \\
\text { Strategic }\end{array}$ & $\begin{array}{l}\text { 1. Reserve margin } \\
\text { 2. Beban puncak per wilayah }\end{array}$ \\
\hline $\begin{array}{l}\text { Pemetaan } \\
\text { Potensi } \\
\text { Pembangkit }\end{array}$ & $\begin{array}{l}\text { 1. Aspek geografis suatu wilayah } \\
\text { 2. Cadangan batu bara } \\
\text { 3. Debit air }\end{array}$ \\
\hline
\end{tabular}

\section{Tabel 1. Variabel Penelitian}




\section{III.Diagram Sebab Akibat}

Pembuatan model bertujuan untuk mengetahui pola perilaku dan hubungan antar variabel. Diagram sebab akibat adalah diagram yang bertujuan untuk menggambarkan bagaimana variabel-variabel tersebut saling terkait. Gambar di bawah ini menunjukkan hubungan antar satu variabel dengan yang lain.

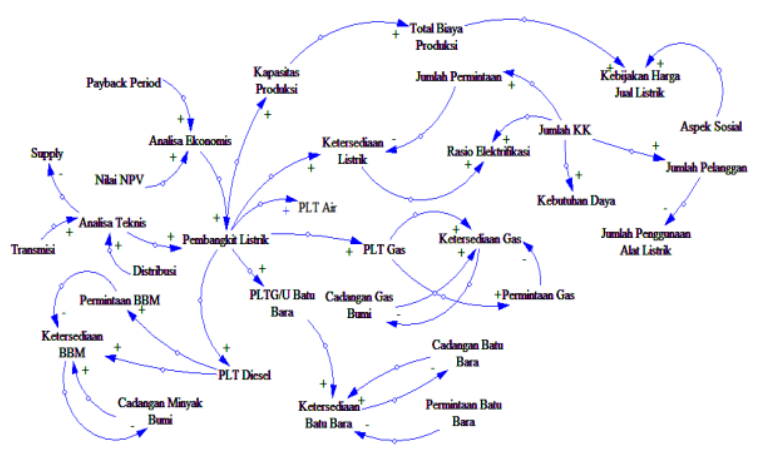

Gambar 4. Diagram Sebab Akibat

\section{Validasi Model}

Validasi adalah proses untuk menentukan apakah model sudah mewakili sistem yang sebenarnya atau belum. Model akan valid apabila nilai E1 tidak lebih dari 0.05 atau 5\% dan nilai E2 tidak boleh lebih dari 30\%. berikut adalah hasil validasi model dari permintaan energi listrik pulau Madura. Hasil membuktikan bahwa model sudah valid.

Tabel 2. Tabel Validasi Mean Validation

\begin{tabular}{ll}
\multicolumn{1}{c}{ Mean Comparison } & \multicolumn{1}{c}{ Valid E1 $\leq \mathbf{5 \%}$} \\
\hline Bangkalan Regency & $1 \%$ \\
Sampang Regency & $0.95 \%$ \\
Pamekasan Regency & $1.06 \%$ \\
Sumenep Regency & $1.52 \%$
\end{tabular}

Tabel 3. Tabel Validasi Error Variance

\begin{tabular}{ll}
\multicolumn{1}{c}{ Error Variance } & Valid E2 $\leq \mathbf{3 0 \%}$ \\
\hline Bangkalan Regency & $1.53 \%$ \\
Sampang Regency & $0.85 \%$ \\
Pamekasan Regency & $3.63 \%$ \\
Sumenep Regency & $2.89 \%$
\end{tabular}

\section{Pembuatan Dashboard}

Data yang divisualisasikan dalam bentuk grafik akan lebih mudah untuk dibaca dan dianalisa secara menyeluruh sebagai bahan pertimbangan bagi para pemangku keputusan. Pihak manajemen, dalam hal ini adalah PT PLN mengidentifikasi peluang dan hambatan

\section{Pertumbuhan Energi Listrik di Pulau Madura}

Pertumbuhan permintaan energy listrik di Pulau Madura sekitar 9\% setiap tahunnya dan jumlah ini semakin meningkat. Berikut ini adalah visualisasi pertumbuhan permintaan energy listrik untuk Kabupaten utama di Madura mulai tahun 2000 sampai 2040. Dari data dapat dilihat bahwa Kabupaten Pamekasan Memiliki kebutuhan energi listrik yang paling besar.

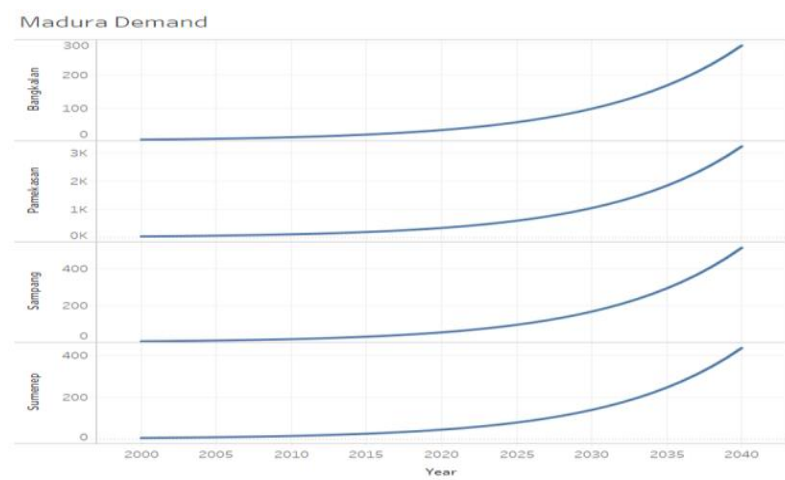

Gambar 5. Tampilan Dashboard untuk Pertumbuhan Permintaan Energi Listrik Pulau Madura

\section{Perencanaan Kapasitas Terpasang per Wilayah}

Untuk meningkatkan rasio elektrifikasi dan menjaga keberlanjutan pasokan listrik untuk memenuhi kebutuhan pelanggan, maka PT PLN perlu merencanakan kapasitas pembangkit listrik yang nantinya dapat menangani beban puncak masing-masing region. Berikut grafik visualisasi perencanaan kapasitasi untuk kepulauan Madura. Kabupaten Pamekasan direncanakan memiliki kapasitas sebesar 64.74 mw, Kabupaten Bangkalan 55.12 mw, Kabupaten Sampang 57.3 mw dan Kabupaten Sumenep 54.5 mw. Sedangkan untuk pulau kecil tidak memiliki kapasitas terlalu besar. Pulau Sapudi direncanakan sebesar $1.56 \mathrm{mw}$, Pulau Sapeken $0.48 \mathrm{mw}$, Pulau Mandangin $0.6 \mathrm{mw}$, Pulau Kangean 2.64 mw dan Pulau Gili Genting 5.4 mw. Total kapasitas adalah $242.3 \mathrm{mw}$.

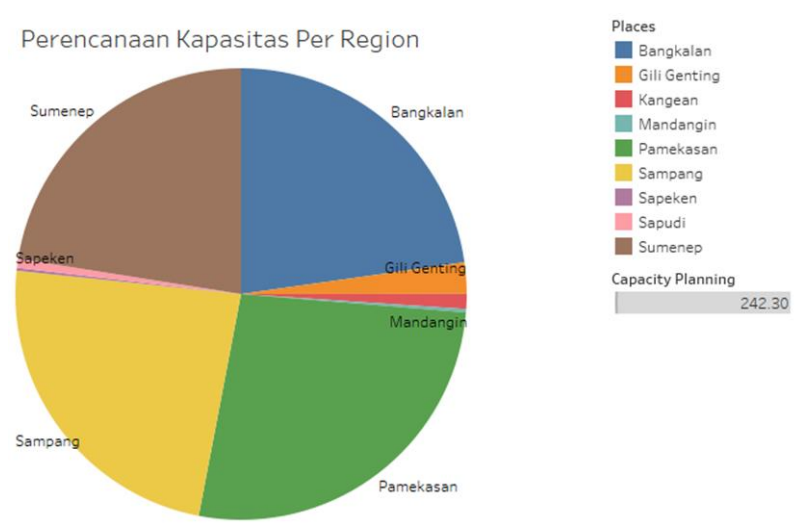

Gambar 6. Tampilan Dashboard untuk Perencanaan Kapasitas Terpasang Masing-Masing Wilayah

\section{Pemetaan Potensi Lokasi Pembangkit}

Pulau Madura memiliki beberapa sumber daya alam, baik itu sumber daya alam fosil maupun sumber daya alam terbarukan. Sumber daya alam tersebut nantinya 
dapat digunakan sebagai bahan penggerak generator pembangkit listrik. Sumber daya alam tersebut tersebar di beberapa kabupaten utama Pulau Madura. Berikut adalah tampilan visualisasi pemetaan daerah lokasi yang berpotensi untuk dikembangkan pembangkit listrik guna memenuhi kebutuhan energy listrik Pulau Madura.

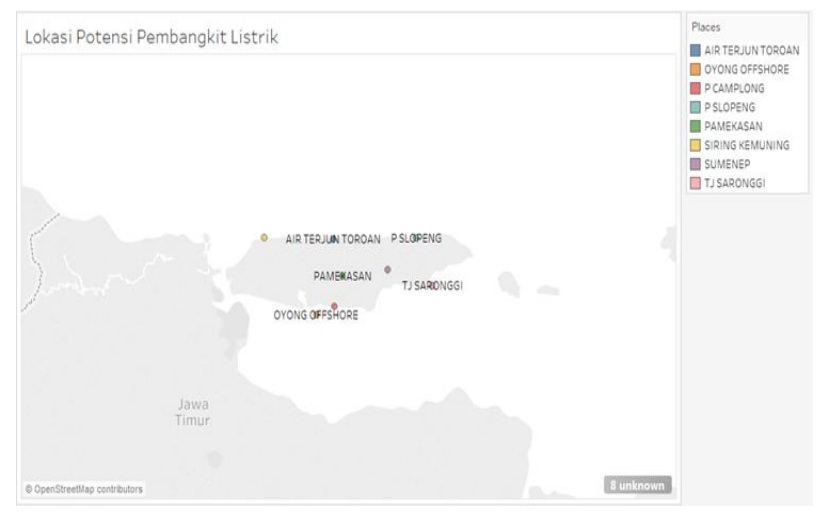

Gambar 7. Pemetaan Lokasi Potensi Pembangkit Listrik di Pulau Madura Berdasarkan Sumberdaya Alam yang Dimiliki

\section{Kesimpulan}

Dari penelitian ini dapat disimpulkan:

1. Dalam merencanakan kapasitas pembangkit listrik terdapat beberapa aspek yang perlu diperhatikan. Diantaranya adalah permintaan energi listrik tahunan, beban puncak pembangkit per wilayah serta spare beban (reserve margin) sebesar $20 \%$ dari daya terpasang.

2. Dari data dapat disimpulkan bahwa total kapasitas yang direncakan agar memenuhi kebutuhan listrik per wilayah dan diharapkan dapat miningkatkan rasio elektrifikasi Pulau Madura adalah sebesar $242.3 \mathrm{~mW}$.

3. Pembuatan aplikasi Dashboard Strategic dimaksudkan agar para pemangku keputusan dapat memperhatikan setiap variable yang terkait dalam perencanaan kapasitas pembangkit. Dengan adanya aplikasi ini diharapkan penyampaian informasi terkait kondisi di lapangan kepada para pemangku keputusan dapat tersampaikan dengan lebih komunikatif.

\section{Daftar Pustaka}

Anwar, M. K., 2011. Analisa Pembangunan PLTU Madura Kapasitas $2 \times 200 \mathrm{mw}$ Sebagai PRogram 10.000 mw PT PLN Bagi Pemenuhan Kebutuhan Listrik di Pulau Madura. Surabaya, s.n.

Axella, O. \& Suryani, E., 2012. Aplikasi Model Sistem Dinamik untuk Menganalisis Permintaan dan Ketersediaan Listrik Sektor Industri. Jurnal Teknik ITS, Volume 1, pp. 339-344.
Barlas, Y., 1996. Multiple Test for Validation of Sistem Dynamics Type of Simulation Model. Turkey: s.n.

Few, S., 2006. Information Dashboard Design. s.1.:O'Reilly.

Forrester, J. W., 1968. Principle of Sistem. Massachutsetts: Wright-Allen Press Inc..

Januarita, D. \& Dirgahayu, T., 2015. Pengembangan Dashboard Information Sistem (DIS) Studi Kasus: Lembaga Penelitian dan Pengabdian (LPPM) di ST3 Telkom Purwokerto. Jurnal Infotel, VII(2), pp. 165169.

Marsudi, D., 2011. Pembangkitan energi Listrik. Jakarta: Erlangga.

Mayer, P. C., 2000. Reliability economies of scale for tropical island electric power. Energy Economics, Issue 2, pp. 319-330.

Pamudji, N., 2014. Rencana Usaha Penyediaan Tenaga Listrik 2015-2024, Jakarta: PT PLN (Persero).

Suryani, E., 2006. Pemodelan dan Simulasi. Yogyakarta: Graha Ilmu.

Sutrisna, K. \& Rahardjo, A. P., 2009. Pembangkit Listrik Masa Depan Indonesia, Bandung: s.n.

Winardi, 1989. Pengantar Tentang Teori Sistem dan Analisis Sistem. Bandung: Mandar Maju. 